\title{
Energy, Population and the Urban Canopy: An Integrated GIScience Approach Towards Modeling Human-Environmental Interactions
}

\author{
Ryan R. Jensen and Jay D. Gatrell* \\ Department of Geography, Brigham Young University, Provo, UT 84602 \\ Telephone: 801-422-5386, Fax: 801-422-0266, E-mail: rjensen@byu.edu \\ *Department of Geography, Geology and Anthropology, College of Arts and Sciences, \\ Indiana State University, Terre Haute, IN 47809
}

KEYWORDS Leaf Area Index. Remote Sensing. Artificial Neural Networks. Casetti. Urban Energy Usage

\begin{abstract}
This paper examines the interaction between socio-demographic characteristics (electrical energy usage, population density, and percentage of owner occupied dwellings) and the ability of these characteristics to predict urban leaf area index using ordinary least squares regression (OLS). Urban leaf area index was estimated using a combination of field work, remote sensing, and artificial neural networks, and socio-demographic data were obtained from the United States Census 2000. Results show that the independent variables statistically accounted for about $11 \%$ of observed variance in urban leaf area, underscoring the impact of socio-demographic characteristics on natural features in urban environments. Further, the study demonstrates that the interaction between built and natural environments can be effectively modeled using proxy data obtained from remote sensing platforms. The paper also shows the efficacy of using interaction terms to model human-environment interactions. Studies like this may be used by urban researchers, planners, government officials, and others to understand the demographic forces that help to shape urban environments.
\end{abstract}

\section{INTRODUCTION}

\section{Energy, Population, and the Urban Canopy}

The practice of GIScience and migration of integrated Geographic Information Systems (GIS) and Remote Sensing methodologies across the academy signifies the maturation of one of the discipline's most significant conceptual and practical applications to the geosciences in particular and the broader social sciences in general. As part of the maturation process, GIScience can and should articulate new intersections within and between established methodologies, particularly from spatial analysis literature (see Fotheringham 1992; 1992; 1997). In this paper, we examine the interaction between human and physical parameters within an urban area and the ability of these parameters to predict leaf area index using ordinary least squares regression (OLS). The paper examines the case of Terre Haute, Indiana USA to determine the

Corresponding author:

Ryan R. Jensen, Department of Geography

Brigham Young University, Provo, UT 84602

Telephone: 812-232-4134

Fax: 812-237-8029

E-mail: rjensen@byu.edu efficacy of developing and implementing a hybridized GIScience framework that draws from applied GIS and remote sensing — as well as spatial statistics.

To test this hypothesis, this study develops a single model that investigates the relationship between summertime household energy consumption, three market oriented (or consumer) variables: population, population density, and owner occupied dwellings, and estimated urban forest canopy using the leaf area index (LAI) method. The results are used to determine if the expansion method can be used to derive an effective terminal regression model using human and environmental variables. The expansion method, developed by Casetti (1972), is a statistical approach in geography that more effectively estimates regression equations, reduces the total number of independent variables in a model, and accounts for the variation (or varying relationships) across space. In the following pages, the paper: (1) examines the related literature on urban forestry and energy consumption, (2) defines the expansion method and its potential to human-environment interactions in urban environments; (3) outlines data collection and defines the models; and (4) concludes with a discussion of the results and the overall study implications. 


\section{Energy Consumption and Urban Trees}

Urban trees provide many tangible and intangible benefits to communities. One of the main tangible benefits of urban trees is their contribution to energy conservation by helping to reduce the cost of heating and cooling buildings (Dwyer et al. 1992). Urban forests modify climate and energy use through 1) shading, which reduces the amount of solar energy absorbed and stored by built surfaces; 2) evapotranspiration, which cools the air by converting water in plants into a vapor; and 3) wind speed reduction, which reduces infiltration of outside air (Simpson 2002). For example, Geiger (2002) showed that strategically placed shade trees reduce annual air condition energy use by $6,400 \mathrm{GWh}$ - equivalent to over 7 100-MW power plants. California utilities save about $\$ 500$ million annually in wholesale electricity purchases and generation costs, customers save about $\$ 1$ billion in retail electricity costs, and peak load is reduced by about 10 percent. Jensen et al. (2003) showed that for every one unit increase in leaf area index, $\mathrm{KwH} /$ day usage decreased by $4.17 \mathrm{KwH}$. Akbari et al. (1990) estimated 11\% energy savings at the city scale based on 15\% canopy cover and 19\% urban albedo.

\section{Human-Environment Interactions and the Casetti Method}

In 1972, Casetti proposed that geographers develop new statistical models that account for spatial variation. The result of Casetti's work has been the proliferation of new methodologies that are theoretically grounded and provide the necessary building blocks for modeling complex and contextual realities for data that "exhibit spatial nonstationarity" (Fotheringham 1997, p. 89; (Casetti and Jones 1992, p. 2). In practice, a variety of approaches towards modeling "spatial variation" and "local contingency" have emerged including the expansion method and geographically weighted regression. In this paper, the study model creates an interaction term that contextualizes the empirical analysis by examining the specific interaction between model terms "in place". The use of an interaction term enables the model to statistically account for local contingencies that shape socio-spatial relationships within and across space (see Jones and Hanham 1995). Within the context of this analysis and GIScience more broadly, the use of interaction terms proves to be an effective device for modeling complex socio-spatial relationships in urban environments. Likewise, the use of simple interactions coupled with a conceptual emphasis on contingency make the approach an effective framework for integrating GIS and remote sensing data across multiple scales.

\section{DATA}

Leaf Area Index: This study quantified the urban forest in Terre Haute by measuring leaf area index (LAI), $\mathrm{m}^{2}$ of leaves per $\mathrm{m}^{2}$ of ground, throughout the city. LAI was measured using a Decagon AccuPAR Ceptometer that measures photosynthetically active radiation $(0.40-0.70$ $\mathrm{mm}$ ) above and below forest canopies. These PAR measurements are then applied to the Gap Fraction theory. Gap fraction theory states that for whole canopies, the decrease in light intensity (light attenuation) with increasing depth can be described by the equation

$I L / I O=e^{-k L A I(L)}$

where $I L / I O$ is the percentage of incident light at the top of the canopy $(I O)$ reaching depth $L$ in the canopy, $L A I$ is the cumulative LAI from the top of the canopy to point $L, k$ is a stand or species specific constant, and $e$ is the base of natural logarithms (Larcher 1975; Aber and Melillo 1991). PAR measurements were made on each corner of $20 \times 20 \mathrm{~m}$ quadrats in each cardinal direction and averaged in 118 random locations (Fig. 1). Global positioning system (GPS) points were taken in the middle of each quadrat for later input into a Geographic Information System (GIS) program to extract remotely sensed brightness values.

It was not feasible to measure LAI at every location in Terre Haute, so these point LAI values were integrated with remote sensing imagery and an artificial neural network (ANN) to estimate LAI over those parts of the community where LAI was not measured in situ. This was done using the GPS locations to extract interpolated reflectance values from Advanced Spaceborne Thermal Emission Radiometer (ASTER) imagery in the GIS. In ASTER's visible-near infrared subsystem, it measures reflectance in three different portions of the electromagnetic spectrum at 15 by 15 meters: green $(0.52-0.60 \mathrm{~mm})$, red $(0.63-0.69$ $\mathrm{mm})$, and near infrared $(0.76-0.86 \mathrm{~mm})$. The ASTER sensor also measures reflectance in the short-wave infrared at 30 by 30 meter and emittance in the 
thermal infrared at 90 by 90 meters. Shortwave and thermal infrared data were not used in this analysis because of their coarse spatial resolutions. Remotely sensed imagery has often been used in urban analysis. For example, Weng and Lo (2001) used Landsat Thematic Mapper data and found that urban development reduced a scaled Normalized Difference Vegetation Index value by $30 \%$ in the Zhujiang River Delta, China.

Reflectance values and LAI measurements were used to create and train an ANN where LAI was the output and remote sensing reflectance values were the inputs (Jensen, et al. 2003). Multiple network architectures were created and trained with various numbers of hidden layers and different numbers of neurons within each hidden layer. Testing multiple network architectures made certain that network overfitting and underfitting did not occur. After each network was created, spectral values of in situ LAI measurements not used to train the network were used to examine network accuracies. The most accurate network

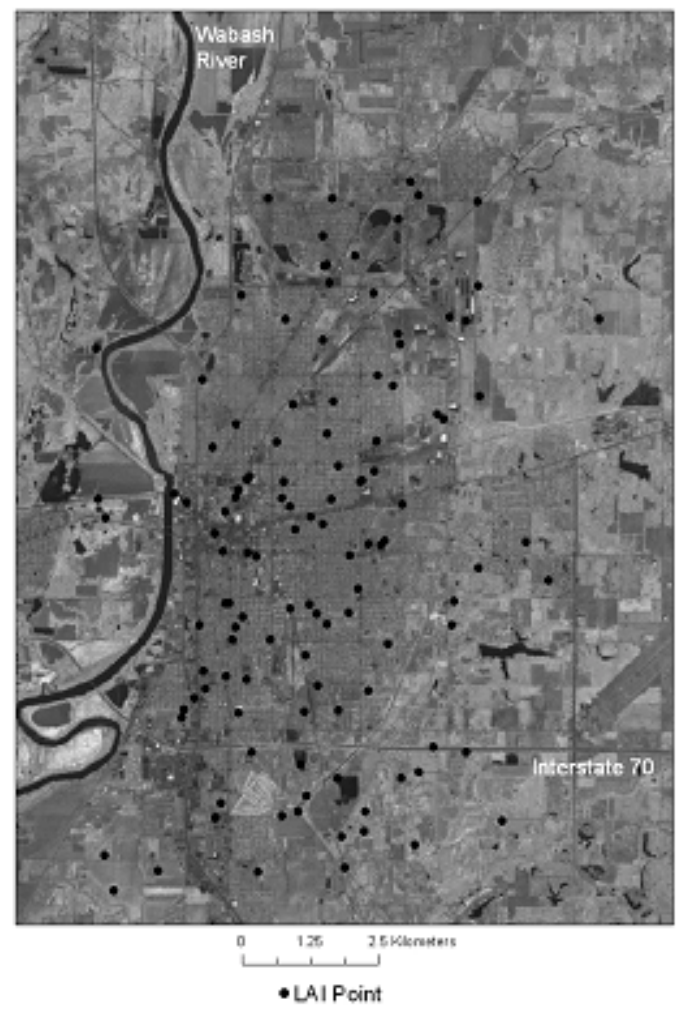

Fig. 1. Near-infrared image of study area with LAI points. had one hidden layer where weighted synapses determined how reflectance values related to LAI measurements.

Household Energy: Privacy laws complicated the acquisition of household electrical usage data because the local utility company, Cinergy PSI, could not release customer-billing information without customer approval. Therefore, a list of 200 random addresses was provided to Cinergy and they returned a listing of kilowatt-hours by billing period for an address on the same city block as the psuedo-address and listed as though it were for the address (Fig. 2). For example, if an address such as " 550 North $13^{\text {th }}$ St." was given to Cinergy, they would return the energy information from a residence on the 500 north block on $13^{\text {th }}$ Street.

This study examined electrical usage during the cooling season, which was defined as April 15 to September 15. Electric meters were read at individual residences once each month, but not all the meters were read on the same day. Some of

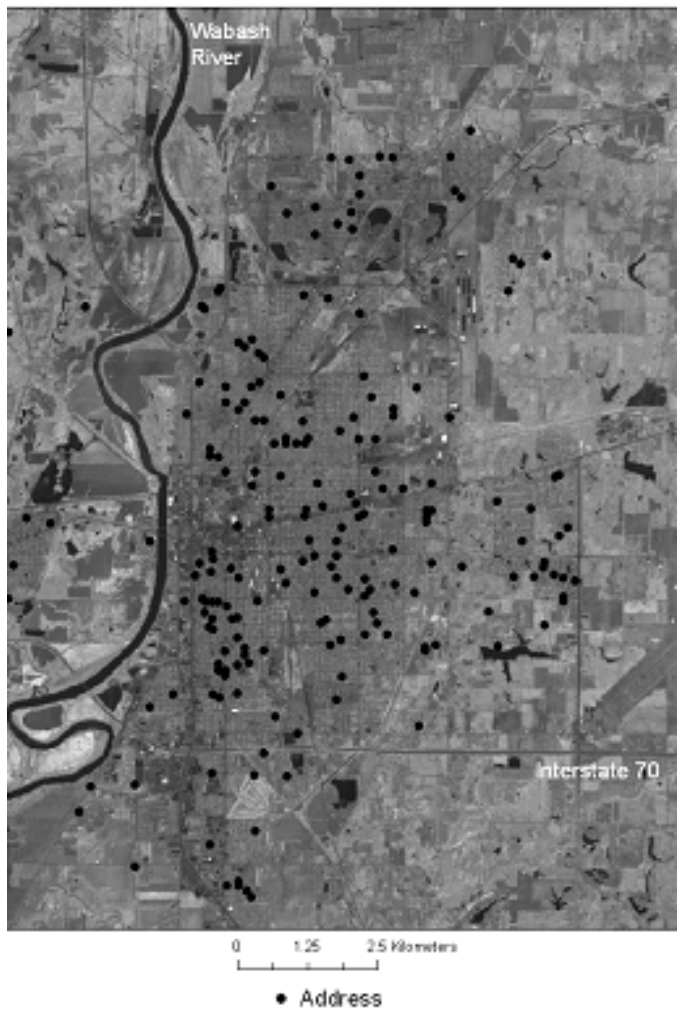

Fig. 2. Location of 200 random addresses overlaid on near infrared image. 
the residences reported had months where the service was disconnected for a period of time; others seemed to have one or more skipped readings. To remedy this, all readings were normalized to a kilowatt hours per day value.

The psuedo-addresses were geocoded to a GIS layer using United States Geological Survey Digital Raster Graphic (DRG) maps used earlier to geo-reference the satellite image. In some cases the USGS map did not show a street at the site of the psuedo-address. For those cases the Internet mapping service, MapQuest, was used to locate the address and its location on the USGS map was estimated as best as possible.

To offset the inability to map the exact location of the residences in the Cinergy database the satellite data were averaged. In the averaging process each pixel was assigned a value equal to the statistical mean of the nearest group of pixels using a three by three pixel block average. For each psuedo-address location, reflectance information was averaged and extracted from the ASTER image in the three bands. Then, using the artificial neural network created previously, LAI values for the psuedo-addresses were estimated.

Census Data: Demographic data were obtained from the published 2000 Census Summary Files 1 (SF1) and 2 (SF2). The following data were extracted at the census block group scale: total population and percent owneroccupancy. Using the Census population data, population density was calculated based on the observed area.

Interaction Terms: An interaction term was created through a simple multiplication process. Specifically, energy values were multiplied by owner occupied structure values. The primary rationale for the specified interaction is rooted in the local geography of the city and a simple assumption that the observed energy consumption should increase in those neighborhoods with lower owner-occupied dwellings (i.e., more rental property, as well as industrial/commercial uses). Given the geography of Terre Haute and its history as a college town, this would be anticipated as multiple housing units within a structure should produce higher consumption rates. Indeed, the correlations presented in Table 2 support this as the observed relationship between $\mathrm{O}$ and $\mathrm{E}$ is slightly negative. In the OLS model presented below, the obtained interaction term then is used to determine if the observed slope change-if any-is statistically significant.
Model: The analysis tested the relationship between observed leaf area index and the independent variables-population, population density, energy consumption, percent owner occupied structures, and the interactions between energy consumption owner occupied structures. The ability of the model to predict observed LAI was tested using ordinary least squares (OLS) regression. The estimated equation is presented in Table 1.

$\mathrm{L}=\alpha+\mathrm{E}+\mathrm{D}+\mathrm{O}+\mathrm{EO}$

Where $\mathrm{L}$ is the leaf area index (LAI); $\alpha$ is a constant; E is observed electricity consumption; $\mathrm{D}$ is population density within a census block group; O represents the percent owner occupied structures; and EO is the interaction between the variables $\mathrm{E}$ and $\mathrm{O}$.

\section{RESULTS}

The model accounted for about $11 \%$ of the variation in urban leaf area $(\mathrm{r}$-square $=.112)$ and was statistically significant $(F=6.103)$. Specifically, LAI is negatively related to energy usage $(-0.102)$ and population density $(-0.248)$. This indicates that as energy usage and population density decrease, LAI increases. Conversely, as LAI increases, both energy usage and population density decrease. LAI is also negatively correlated with the interaction between energy and percent owner occupied dwellings (-0.035). The statistically significant slope change as a result of the interaction demonstrates that the model relationship varies across space and

Table 1: Coefficients and corresponding t-values for the constant and each of the independent variables.

\begin{tabular}{lccccc}
\hline & $\alpha$ & $E$ & $D$ & $O$ & $E O$ \\
\hline b coefficient & 0.6840 & 0.0086 & -0.0002 & 1.2412 & -0.0199 \\
$\mathrm{t}$ & 2.4935 & 1.6942 & -2.8076 & 2.9347 & -2.2950 \\
\hline $\mathrm{r}=.334$ & & & & & \\
$\mathrm{r}-$ square $=.111$ & & & & \\
$\mathrm{f}=6.103$
\end{tabular}

Table 2: Correlation coefficients of the variables.

\begin{tabular}{lcccc}
\hline & LAI & $\begin{array}{c}\text { Energy } \\
\text { density }\end{array}$ & Pop. & $\begin{array}{c}\text { \% Owner } \\
\text { Occ. }\end{array}$ \\
\hline Energy & -0.102 & & & \\
Pop. Density & -0.248 & 0.001 & & \\
\% Owner Occ. & 0.216 & -0.017 & -0.407 & \\
Energy & -0.035 & 0.851 & -0.200 & 0.421 \\
*Owner Occ. & & & & \\
\hline
\end{tabular}


that the observed relationship "accelerates" in neighborhoods with decreased owner-occupied dwellings. The performance of the EO interaction confirms -in part-the assertion that electrical energy usage and owner occupied structures are a key determinant in urban leaf area. LAI is positively related to percent owner occupied dwellings, indicating that as the percentage of owner occupied dwellings increases, LAI increases. This may be a result of home-owners planting more trees and/or caring more for existing trees.

\section{DISCUSSION}

This study shows that the independent variables (energy consumption, population density, and owner-occupied dwellings) statistically account for observed variance in estimated urban leaf area in Terre Haute, IN, USA. While the actual r-square value may seem small, it is important to remember many of the other factors that may be influencing urban leaf area such as soil types, irrigation, neighborhood requirements or conditions, efficiency and/or age of individual air-conditioning units, home insulation, age of home, direction of windows and precautions taken to exclude sunlight from entering the home, window coverings (e.g., miniblinds) color of shingles or rooftop, and general preference of the homeowner (e.g., thermostat setting). It is hoped that future research will use this method in larger urban and suburban areas to examine if this trend is observed elsewhere. In addition, future research could focus on other socio-demographic variables that may influence the extent of the urban forest canopy.

Studies like this may be used by urban researchers, planners, government officials, and others to understand the demographic forces that help to shape 'natural' urban environments. A better understanding of these forces could help professionals to plan new urban/suburban development and manage/maintain existing development to have a robust urban canopy.

\section{REFERENCES}

Aber JD, Melillo JM 1991. Terrestrial Ecosystems. Chicago: Saunders College Publishing.

Akbari H, Rosenfeld AH, Taha H 1990. Summer heat islands, urban trees, and white surfaces. ASHRAE Transactions, 96 (Pt. 1): 1381-1388.

Casetti E 1972. Generating models by the expansion method: Applications to geographic research. Geographical Analysis, 4: 81-91.

Dwyer JF, McPherson EG, Schroeder HW, Rowntree RA 1992. Assessing the benefits and costs of the urban forest. Journal of Arboriculture, 18: 227-234.

Casetti E, Jones JP 1992. An introduction to the expansion method and to its applications. In: JP Jones, E Casetti (Eds.): Applications of the Expansion Method. London: Routledge, pp. 1-9.

Fotheringham AS 1997. Trends in Quantitative Methods, I: Stressing the Local. Progress in Human Geography, 21: 88-96.

Fotheringham AS 1994. Exploratory data analysis and GIS. Environment and Planning A, 24:1675-1678.

Fotheringham AS 1992. On the future of spatial analysis: the role of GIS. Environment and Planning A, (Special Issue): 30-34.

Geiger JR 2002. Green plants or power plants? Davis, California: USDA Forest Service, Pacific Southwest Research Station, Center for Urban Forest Research.

Jensen RR, Boulton JR, Harper BT 2003. The relationship between urban leaf area and household energy usage in Terre Haute, Indiana, USA. Journal of Arboriculture, 29: 226-230.

Jensen R Gatrell J Boulton J and Harper B 2004. Using Remote Sensing and Geographic Information Systems to Study Urban Quality of Life and Urban Forest Amenities. Ecology and Society, 9 [online] URL: http://www.ecologyandsociety.org/vol9/iss5/art5/

Jones JP 1992. Paradigmatic dimensions of the expansion method, In: JP Jones, E Casetti (Eds.): Applications of the Expansion Method. London: Routledge, pp. 42-62.

Jones JP, Casetti E 1992. Applications of the Expansion Method. London: Routledge.

Jones JP, Hanham RQ 1995. Contingency, Realism, and the Expansion Method. Geographical Analysis, 27: 185-207.

Larcher W 1975. Physiological Plant Ecology. New York: Springer-Verlag.

Simpson JR 2002. Improved estimates of tree shade effects on residential energy use. Energy and Buildings, 34: 173-1082.

Weng Q, Lo CP 2001. Spatial analysis of urban growth impacts on greenness with Landsat TM data. Geocarto International, 16: 17-25. 